\title{
Elaboração de queijo tipo "tofu" utilizando castanha-do-brasil (Bertholletia excelsa).
}

\section{Elaboration of tofu cheese using of Brazil nuts (Bertholletia excelsa).}

\author{
Cristiane Silva Braga ${ }^{1}$ \\ Carlos Victor Lamarão2 ${ }^{2}$ \\ Charline Soares dos Santos Rolim ${ }^{3}$ \\ Klenicy Kazumy de Lima Yamaguchi ${ }^{4}$
}

\begin{abstract}
Resumo: Esta pesquisa teve como objetivo elaborar um alimento tipo queijo vegetal "tofu", utilizando castanha-do-brasil (Bertholletia excelsa). Para a determinação da composição centesimal da castanha-do-brasil, as amostras foram analisadas em triplicatas, obtendo-se como resultados os valores de Umidade $(10,16)$, Proteínas (12,35), Lipídios (63,80), Carboidratos $(21,00)$, Fibras $(8,96)$, Cinzas $(2,85)$ e Valor energético $(697,78)$. Foi realizada análise sensorial com duas concentrações do alimento tipo tofu (75 e 100\%), onde verificou-se maior aceitação da concentração de tofu 100\% castanha-do-brasil. Foram realizadas as análises microbiológicas na amostra de tofu com concentração de 100\% castanha-do-brasil, expressando resultados para Coliformes Totais (ausência), Coliformes termotolerantes (ausência), Contagem de Bactérias Aeróbias Mesófilas (92 NMP/g) e Contagem de bolores e leveduras (ausência). Portanto, mostrou-se viável sua produção, tanto do ponto vista nutricional, quanto sensorial, tornando-se alternativa para a agroindústria de produtos lácteos e para os públicos veganos, intolerantes, alérgicos e a pessoas que almejam consumir produtos mais saudáveis.
\end{abstract}

Palavras-chave: Alimentação, Vegano, Agroindústria, Amazonas.

Abstract: This study aimed to prepare a vegetable cheese using Brazil nuts (Bertholletia excelsa). Sample were analyzed in triplicates, resulting in the values Humidity (10.16), Proteins (12.35), Lipids (63.80), Carbohydrates (21.00), Fibers (8.96), Ash (2.85) and Energy Value (697.78). To assess product acceptability, a sensory analysis was performed with two concentrations of tofu-type food (75 and $100 \%$ ), and $100 \%$ Brazil nut tofu was the most accepted by the tasters. Microbiological analyzes were carried out and follow absence to Total Coliforms, Thermotolerant Coliforms, Mesophilic Aerobic Bacteria Count (92 NMP / g) and Mold and yeast count. The production of cheese using Brazil nuts proved to be viable, both from a nutritional point of view, as well as sensory, being a potential alternative for the agroindustry and to vegan / vegetarian consumer, lactose

\footnotetext{
${ }^{1}$ Graduada em nutrição pelo Instituto de Saúde e Biotecnologia da Universidade Federal do Amazonas ${ }^{2}$ Doutor em Biotecnologia. Professor Adjunto na Universidade Federal do Amazonas

${ }^{3}$ Graduanda em Eng. de Alimentos pela Faculdade de Ciências Agrárias Instituição: Universidade Federal do Amazonas

${ }^{4}$ Doutora em Química. Professora Adjunta no Instituto de Saúde e Biotecnologia da Universidade Federal do Amazonas
} 
intolerant, allergic to cow's milk, dyslipidemic and to people who want healthier products. of dairy products and vegetarian consumers.

Keywords: food, vegan, tofu, Amazon .

\section{Introdução}

A alimentação e nutrição são assuntos que de modo geral vem ganhando maior interesse da população. Segundo Dutra-de-Oliveira e Marchini (1998), há diversos fatores que influenciam no consumo dos alimentos, que vão desde preferências a doenças e condições funcionais do trato gastrointestinal.

Em 2011, o Instituto Brasileiro de Opinião Pública e Estatística (Ibope) divulgou uma pesquisa sobre alguns aspectos dos consumidores brasileiros, que revelou resultados expressivos quanto ao interesse da população por cuidados com alimentação, nutrição e escolha dos alimentos, 9\% se declara vegetarianos (IBOPE, 2011). Uma nova pesquisa divulgada em 2018 mostrou que houve aumento no número de brasileiros que se declaravam vegetarianos, de 9\% para cerca de 14\%. Atualmente, cerca de 29,2 miIhões de brasileiros autodeclaram-se vegetarianos (IBOPE, 2018).

De modo geral, considera-se vegetarianismo o regime alimentar que abole carnes ou que consiste na alimentação exclusiva de vegetais (ABONIZIO, 2016). Segundo o Centro Vegetariano (2002), "veganos" (do inglês vegans), são aquelas pessoas as quais não consomem produtos de origem animal, não apenas as carnes, mas também seus derivados como laticínios, ovos, gelatinas, mel, couro, seda e lã, não utilizam produtos testados em animais; e não frequentam espetáculos onde há exploração animal. Atender às condicionalidades de tais opções dietéticas não é tão simples, e acaba induzindo a constante procura de produtos similares aos existentes de origem animal, em versões substitutas.

Deste modo, em virtude das necessidades apresentadas por adeptos ao veganismo, é crescente o mercado de produtos e serviços destinados a este público, não apenas no Brasil, mas em todo o mundo. Nesse contexto, percebe-se que uma grande gama de novos produtos pode atingir simultaneamente três grupos de consumidores: os veganos, os intolerantes à lactose e as pessoas que controlam a ingestão de colesterol. Apesar de o mercado de alimentos veganos demostrar ser promissor e ter apresentado 
considerável crescimento nos últimos anos, ainda há grandes lacunas em relação a variedade de seus produtos, não suprindo todos os anseios e necessidades deste público específico.

Um dos alimentos lácteos mais apreciados pelos brasileiros é o queijo, comumente consumido em todas as regiões do Brasil. Segundo Tafarel (2012) em sua pesquisa, o queijo foi indicado como um dos alimentos que mais causam falta aos veganos no supermercado. O queijo, possui como substituto alternativo, o "Tofu”, que é o queijo vegetal à base de soja, disponível no mercado brasileiro, entretanto, devido ao sabor singular da soja, não apresenta grande aceitação por parte da maioria dos consumidores, requerendo assim melhoramentos que viabilizem uma melhor palatabilidade (PAULETO et al., 2012).

Nesse contexto, temos a região amazônica, que é possuidora de uma riqueza imensurável, com inumeráveis frutos com altos valores nutritivos e de grande importância econômica, que necessitam de pesquisa tecnológica, de modo a transformá-los em produtos estáveis, e incentivar a utilização de suas matérias-primas, seja pelo consumo in natura, ou pela transformação industrial, originando novos produtos para o mercado consumidor (SOUZA, 2003). A utilização de produtos florestais não madeireiros (PFNM) amazônicos para a elaboração de novos alimentos não agride a natureza e/ou os animais e torna-se uma opção mais aceitável ao paladar do público vegano/vegetariano, além de possibilitar a geração de renda alternativa para os produtores locais.

Esta matéria-prima tem papel socioeconômico importantíssimo na região, uma vez que a castanha-do-Brasil é responsável pelo sustento de muitas famílias extrativistas moradoras da região amazônica. Mesmo sendo muito consumido no país, o alimento encontra fluxo de vendas forte em países europeus e na América do Norte, sendo consumido in natura ou como ingrediente de produtos industrializados (FELBERG et al, 2004).

Vale lembrar que não só as sementes são utilizadas, mas também elementos como a casca da árvore (para o preparo de chás) e a madeira (que pode ser utilizada na construção civil). Para evitar o desmatamento desenfreado, a Lei 12.651/2012, impõe que apenas madeira de reflorestamento seja utilizada para fins madeireiros. Muitos outros benefícios comerciais podem ser obtidos desta planta: o óleo da semente (na 
cosmética, culinária e fitopatologia) e a casca (na fabricação de tapetes e peças de artesanato) (BRASIL, 2002).

As possibilidades são inúmeras para essa matéria-prima. Além do uso comum na alimentação, a amêndoa já compõe ingredientes na produção, por exemplo, de castanhas cobertas com chocolate ou iogurte e também como salgado, apenas com sal e condimentos do tipo ervas e pimenta. É fato que os produtos derivados da castanha-doBrasil têm excelente aceitação pelos consumidores brasileiros e de outros países (MARTINS, 2010). Deste modo, este estudo teve como objetivo a elaboração de um alimento tipo queijo vegetal "tofu", utilizando castanha-do-brasil (Bertholletia excelsa) como uma nova alternativa alimentar para o público vegano/vegetariano, intolerantes à lactose, alérgicos ao leite de vaca, dislipidêmicos e a pessoas que almejam o consumo de produtos mais saudáveis.

\section{MATERIAL E MÉTODOS}

\subsection{Aquisição da amostra e processamento da castanha-do-brasil}

As amostras em estudo consistiram de um produto amazônico muito popular na região norte do país, a Castanha-do-brasil (Bertholletia excelsa), coletadas na Feira Municipal de Tefé, no Amazonas. As amostras foram identificadas e acondicionadas em sacos plásticos, recolhidas e armazenadas sob refrigeração para serem encaminhadas ao Laboratório de Produtos Agrícolas, na Faculdade de Ciências Agrárias, da Universidade Federal do Amazonas, na cidade de Manaus-AM. Os demais produtos foram comprados a granel no Mercado Municipal de Manaus.

\subsection{Determinação da composição centesimal da castanha-do-brasil}

Para determinação da composição centesimal da castanha-do-brasil foram realizadas análises físico-químicas de umidade, proteínas, lipídios, fibras totais, cinza, conforme os procedimentos do Instituto Adolfo Lutz (2008). A umidade (por secagem), foi realizada em triplicata, utilizando cerca de três gramas de amostras frescas, foram pesadas em cadinhos desumidificado e submetidos a desidratação em estufa à $105^{\circ} \mathrm{C}$ por três horas. Para a determinação dos teores de proteínas foi realizado o método de Kjeidahl, desenvolvido em três etapas: digestão onde aproximadamente 0,2 g de amostra, 
com duas gramas de mistura catalítica e $5 \mathrm{~mL}$ de ácido sulfúrico; destilação em destilador utilizando $\mathrm{NaOH} 50 \%$ como neutralizador e ácido bórico para depender do teor de nitrogênio; e titulação com ácido clorídrico $\mathrm{HCl} 0,02 \mathrm{~N}$ usando como indicador fenolftaleína até a coloração rosa clara.

Os teores da fração lipídica foram determinados pelo método de Bligh \& Dyer onde uma alíquota de duas gramas da massa triturada foi adicionada em tubos de ensaios com $10 \mathrm{~mL}$ de clorofórmio, $20 \mathrm{~mL}$ de metanol e $8 \mathrm{~mL}$ de água destilada (1:2:0,8), colocados em um agitador rotativo por 30 minutos. Após os 30 minutos adicionou-se mais $10 \mathrm{~mL}$ de clorofórmio e $10 \mathrm{~mL}$ de uma solução de sulfato de sódio (1,5\%). Em seguida, agitouse por mais dois minutos. Após esse processo foi feito a filtragem, mensurado $5 \mathrm{~mL}$ do filtrado e levado para a estufa à $100^{\circ} \mathrm{C}$ até a evaporação completa do solvente. As quantidades de fibras totais foram determinadas através da matéria prima desengordurada por meio da digestão ácida com ácido sulfúrico e incineração em mufla a $550^{\circ} \mathrm{C}$.

Os teores de cinzas foram obtidos, através da incineração de três gramas da amostra em mufla a $550^{\circ} \mathrm{C}$, por aproximadamente duas horas para a queima de toda matéria orgânica. Os resultados foram expressos em porcentagem de cinzas. $O$ teor de carboidratos foi obtido por diferença. O cálculo do valor calórico foi realizado utilizando os fatores de conversão determinados na Resolução De Diretoria Colegiada - RDC no 40 (BRASIL, 2001), que consiste na diferença entre os outros parâmetros, ou seja, é o somatório das porcentagens de umidade, proteínas, lipídios e cinzas, subtraídas de 100, conforme a fórmula a seguir: $E=100-(A+B+C+D)$, onde $A=$ proteína total; $B=$ extrato etéreo (lipídios); $C=$ Umidade; $\mathrm{D}=$ cinzas.

\subsection{Desenvolvimento do produto}

O produto da pesquisa obedeceu às orientações da Embrapa para a confecção de tofu artesanal, sugeridas por Benassi et al. (2007). Inicialmente realizou-se a produção do leite da castanha (2 litros) e o leite de soja (1,5 litros). Os grãos de soja ( $800 \mathrm{~g}$ ) foram hidratados por \pm 16 horas, e as castanhas-do-Brasil $(1 \mathrm{~kg})$ foram descascadas. Em seguida os grãos de soja foram drenados e macerados até a retirada da película.

Considerando-se a água previamente absorvida pelos grãos, adicionou-se a quantidade de água aquecida a $90^{\circ} \mathrm{C}$ suficiente para completar $1200 \mathrm{~mL}$ (soja) e $1500 \mathrm{~mL}$ 
(castanha-do-Brasil). A trituração a quente $\left(90^{\circ} \mathrm{C}\right)$ foi realizada em liquidificador doméstico (700 wats), durante três minutos em velocidade média a alta.

Em seguida foi realizado o cozimento dos extratos, que posteriormente foram transferidos para um recipiente de quatro litros e deixando-os resfriar até $75^{\circ} \mathrm{C}$. Preparouse a solução do agente coagulante (sulfato de magnésio) dissolvendo-o em $40 \mathrm{~mL}$ de água destilada aquecida a $60^{\circ} \mathrm{C}$, adicionando-se aos extratos, homogeneizando-os manualmente, com auxílio de um bastão de vidro e deixados em descanso por 40min. Realizou-se o fracionamento de três concentrações do produto: $50 \%$ castanha-do-brasil e $50 \%$ de soja, $75 \%$ castanha-do-brasil e $35 \%$ de soja e $100 \%$ castanha-do-brasil. Realizou-se o corte do coágulo através de movimentos lentos e perpendiculares, filtrouse totalmente o soro e adicionou-se o ágar-ágar, previamente dissolvido em $40 \mathrm{~mL}$ de água destilada a $80^{\circ} \mathrm{C}$, misturando-os em liquidificador doméstico (700 wats) para homogeneizar a massa, em velocidade dois, durante três minutos. Para enformagem, foram transferidos para recipiente plástico de $250 \mathrm{~g}$, de formato arredondado com tampa. As formulações foram levadas para refrigeração em geladeira a $8^{\circ} \mathrm{C}$ por $24 \mathrm{~h}$, para a estabilização do produto. Posteriormente foram cortados em fatias, embalados, e armazenados em geladeira para a realização das subsequentes análises.

\subsection{Análise Sensorial}

Realizou-se a análise sensorial de duas concentrações do produto (75 e 100\% castanha-do-brasil) com 63 provadores, adultos (acima de 18 anos) não treinados. Foram servidos $10 \mathrm{~g}$ de cada amostra do tofu $75 \%$ e $100 \%$ castanha-do-brasil, em bandejas de inox composta de água, papel toalha, ficha de avaliação e caneta, distribuídas sobre as bancadas do laboratório (Análise Sensorial) com assentos individualizados e iluminados com luz ambiente, mantendo certa distância entre os julgadores para evitar interferência nas opiniões dos mesmos e submetidas ao teste efetivo de aceitação por escala hedônica de 9 pontos, com escore variando de 9 "gostei muitíssimo" até 1 "desgostei muitíssimo", quanto aos atributos sensoriais de aparência, textura, aroma e sabor e aceitação global do produto. Para a avaliação de intenção de compra os provadores não treinados foram orientados a se comportarem como se estivessem prestes a comprar o produto, fazendo uso de ficha constando de escala hedônica verbal de 5 pontos, com escore variando 
de 5 "certamente compraria" até 1 "certamente não compraria". O referido projeto foi submetido e aprovado pelo Comitê de Ética em Pesquisa da Universidade Federal do Amazonas - UFAM, e apresenta parecer $n^{\circ}$ CAAE: 23305619.7.0000.5020.

\subsection{Análises Microbiológicas do Produto Elaborado}

Após a obtenção dos resultados da análise sensorial, verificou-se que a formulação mais aceita pelos provadores foi a amostra 100\% castanha-do-brasil, sendo selecionada para a realização das análises microbiológicas, com instituto de verificar a qualidade de processamento, higiene e manipulação da amostra do tofu de castanhado-brasil. Os procedimentos das análises foram de acordo com a Resolução Diretoria Colegiada - RDC o 12, de 02 de janeiro de 2001 da ANVISA, segundo as metodologias descritas no Compendium of Methods for the Microbiological Examination of Foods (DOWNES; ITO, 2001). Uma alíquota de $25 \mathrm{~g}$ de tofu de castanha-do-brasil foi colocada em frascos autoclavados com $225 \mathrm{~mL}$ de água peptonada a $0,1 \%$, agitadas e homogeneizada e sequencialmente foram realizadas três diluições seriadas. Destas três diluições foram retirados $1 \mathrm{~mL}$ para tubos de ensaios contendo um tubo de Duhan investido e 9 $\mathrm{mL}$ de Caldo Lauril Sulfato de Sódio (LST) e a $45^{\circ} \mathrm{C}$ em Caldo Verde Brilhante (VB), em triplicatas (KORNACKI; JOHNSON, 2001).

A cada 24 horas foram realizadas as leituras das análises (caldo LST e caldo VB) e estimada a quantidade de colônias pelo NMP (Número Mais Provável), segundo a American Public Health Association (APHA, 2001), para determinação de coliformes totais. Também foram semeadas da segunda diluição $50 \mu \mathrm{L}$ em meio de cultura PCA e EMB, realizadas pelo método de plaqueamento em profundidade de acordo com metodologia da American Public Health Association (APHA, 2001), com incubação por $24 \mathrm{~h}$ a $36+1^{\circ} \mathrm{C}$, com diluições de $10^{-1}, 10^{-2}$ e $10^{-3}$. Os resultados foram expressos em presença ou ausência de UFC/g.

Em seguida foram semeados em tubos contendo o meio Escherichia coli (EC) (Merc), mantidos em banho-maria (Marconi $\AA$, modelo MA126) a $44,5^{\circ} \mathrm{C}$ por 24 a $48 \mathrm{~h}$ para verificação da formação de gás. Para a contagem de leveduras e bolores, utilizouse o meio Sabouraud suplementado com cloranfenicol $2 \%$, foi realizado o método de plaqueamento em profundidade de acordo com metodologia da American Public Health 
Association (APHA, 2001), os resultados foram expressos em presença ou ausência de UFC/g (BEUCHAT e COUSIN, 2001).

\section{RESULTADOS E DISCUSSÃO}

A determinação da composição centesimal de um alimento é de fundamental importância, pois demostra de forma básica o valor nutritivo de um produto, delineando seus principais componentes, gerando informações assimiláveis para a escolha sob os aspectos de qualidade e quantidade, possibilitando melhor tomada de decisão aos consumidores. As amostras da castanhas-do-brasil utilizadas na pesquisa foram caracterizadas sob os aspectos físico-químicos, apresentando os resultados expostos na tabela 1.

Tabela 1. Resultados médios dos teores de umidade, proteínas, lipídios, carboidratos, fibras alimentares, cinzas e valor calórico, comparados com os dados de referências bibliográficas (TACO, 2011; IBGE, 2011 e artigos científicos).

\begin{tabular}{|c|c|c|c|c|c|c|}
\hline \multirow[b]{2}{*}{$\begin{array}{l}\text { Parâmetro } \\
\text { Analisado }\end{array}$} & \multirow[b]{2}{*}{$\begin{array}{c}\text { Determinação } \\
(\%)\end{array}$} & \multirow[b]{2}{*}{$\begin{array}{l}\text { TACO } \\
\text { (2011) }\end{array}$} & \multirow[b]{2}{*}{$\begin{array}{l}\text { IBGE } \\
(2011)\end{array}$} & \multicolumn{3}{|c|}{ Artigos científicos } \\
\hline & & & & $\begin{array}{c}\text { SOUZA \& } \\
\text { MENEZES } \\
(2004)\end{array}$ & $\begin{array}{c}\text { FREITAS \& } \\
\text { NAVES } \\
(2010)\end{array}$ & $\begin{array}{l}\text { BALBI } \\
(2014)\end{array}$ \\
\hline Umidade & $10,16 \pm 1,0$ & 3,52 & - & 3,13 & 3,10 & - \\
\hline Proteínas & $12,35 \pm 0,02$ & 14,54 & 14,32 & 14,29 & 14,11 & 14,28 \\
\hline Lipídios & $63,80 \pm 0,2$ & 63,50 & 66,43 & 67,30 & 64,94 & 67,52 \\
\hline $\begin{array}{c}\text { Carboidrato } \\
\text { s }\end{array}$ & 21,00 & 15,10 & 12,27 & 3,42 & 6,27 & 6,56 \\
\hline Fibras Totais & 8,96 & 7,93 & 7,50 & 8,02 & 8,02 & 3,64 \\
\hline Cinzas & $2,85 \pm 0,5$ & 3,40 & - & 3,84 & 3,56 & 3,65 \\
\hline $\begin{array}{c}\text { Valor } \\
\text { energético }\end{array}$ & 697,78 & 643,0 & 656,0 & 676,0 & 665,98 & 691,0 \\
\hline
\end{tabular}

Um dos parâmetros mais importantes para avaliação de um alimento em relação ao seu estado de conservação; é o índice de umidade, pois está inteiramente ligado à sua estabilidade e à qualidade, e, por conseguinte, estabelece a validade do alimento (BALDI, 2014). O ambiente também pode ser um grande influenciador na velocidade das alterações que ocorrem em alimentos. De acordo com Andrade (2008), se a umidade do 
ambiente for baixa, o alimento pode desidratar e se for elevada pode absorver água do ambiente, o que ocasionaria perda na qualidade devido o desenvolvimento de fungos, além disso, outros pontos devem ser considerados, como a embalagem, a maneira e local de estocagem das castanhas.

Nas amostras analisadas o valor expresso de umidade totalizou média de 10,16\%, o que sugere ser pouco perecível, mesmo mostrando-se diferente das médias de valores apresentados pela Tabela Brasileira de Composição dos Alimentos (TACO, 2011); e por Souza e Menezes (2004), que são respectivamente de 3,52\% e 3,13\%, podendo este resultado estar relacionado ao transporte das amostras de seu local de origem para outra cidade, considerando as alterações de ambiente e de embalagem, fatores que podem implicar no teor de umidade de um produto.

Quanto ao teor de proteínas resultante foi de $12,35 \%$ revelando-se ligeiramente menor que o fornecido pela Tabela Brasileira de Composição de Alimentos (TACO, 2011), pela Tabela de Composição Nutricional dos Alimentos Consumidos no Brasil (IBGE, 2011), por Souza e Menezes (2004), por Freitas e Naves (2010) e por Baldi (2014), que apresentaram média de 14,30. Segundo Freitas e Naves (2010), é possível que ocorra algumas variações na composição centesimal de diferentes cultivares, influenciando não exclusivamente na composição de proteínas, mas também em outros nutrientes da amêndoa, como vitaminas e pigmentos, que podem ser afetados também por outro fator, a oxidação, que apesar dessa reação se iniciar na fração lipídica, tais componentes desse alimento sem casca podem ser alterados, devido ao comprometimento de alguns aminoácidos, entre os quais a lisina, é considerada a de maior reatividade (ARAÚJO, 2004). As variações podem ser decorrentes de diferenças no clima, solo, práticas agrícolas e características genéticas da planta (FREITAS; NAVES, 2010).

O teor de lipídios foi de $63,80 \%$, em $100 \mathrm{~g}$ de amostra (tabela 1), sendo semeIhante ao valor de $63,50 \mathrm{~g}$ fornecido pela Tabela Brasileira de Composição de Alimentos (TACO, 2011), próximos aos valores de 67,30g e 67,52g encontrados por Souza (2004) e Baldi (2014). Segundo Chunhieng et al. (2008), o teor de ácidos graxos insaturados, de beta tocoferol e de beta sitosterol no óleo dessa castanha garantem propriedades antioxidantes e de prevenção do colesterol. Ferreira et al. (2006) relata que o óleo bruto da 
castanha contem $85 \%$ de ácidos graxos poli-insaturados, sendo destes $34 \%$ representado pelo ácido graxo poli-insaturado linoleico e 51\% pelo ácido graxo monoinsaturado oleico; e 13\% em ácidos graxos saturados presentes no óleo, os quais são de grande importância para a manutenção da saúde e prevenção de doenças.

A amostra de castanha-do-brasil analisada possui elevado valor energético: $100 \mathrm{~g}$ fornecem 697,78 kcal. Este dado pode ser justificado pelo fato de a castanha-do-brasil ser uma amêndoa com grande quantidade de lipídios como apresentado na tabela de composição (Tabela 1). De acordo com os valores diários de referência de nutrientes (VDR) segundo a Resolução de Diretoria Colegiada N³60 de dezembro de 2003 da Agência Nacional de Vigilância Sanitária (ANVISA), devem ser ingeridas diariamente $55 \mathrm{~g}$ de gorduras totais, o que equivale aproximadamente a porção de sete gramas (duas unidades) de castanha-do-brasil. (BRASIL, 2003). Assim como no estudo de Souza e Menezes (2004) e Balbi (2014) foi verificado que as análises de lipídeos e carboidratos apresentam variações. O valor encontrado de carboidratos, no presente trabalho, foi de $21 \%$ em $100 \mathrm{~g}$ de amostra (Tabela 1 ), muito acima dos valores apresentados nos respectivos estudos, sendo os valores mais próximos os apresentados pela TACO (2011) e na tabela IBGE (2011), 15,10 e 12,27, respectivamente, podendo ser justificado, pela origem diferente da matéria-prima utilizada.

As fibras alimentares apresentam-se em uma concentração de 8,96\%, semelhante aos valores achados por Souza e Menezes (2004) e Freitas e Naves (2010) de (8,02). Esse valor é levemente maior, se comparado à porcentagem informada pela tabela TACO (2011) $(7,9 \%)$, e pela tabela IBGE (7,5\%), o que também pode ser explicado pelas diferenças da origem da matéria-prima, variabilidade genética, grau de maturação e, principalmente, pela presença ou ausência da película marrom que envolve a semente da castanha, o que influenciou grandemente no valor de (3,64\%) apresentado por Balbi (2014), porcentagem muito abaixo dos valores, sendo justificado pela retirada da película marrom da semente anteriormente à análise.

A quantidade de minerais encontrada foi de $2,85 \mathrm{~g}$ em $100 \mathrm{~g}$ de amostra (Tabela 1), valor ligeiramente abaixo do valor apresentado pela Tabela TACO (2011) de $(3,40)$, e dos estudos de Souza e Menezes $(2014)(3,84)$ e de Freitas e Naves $(2010)(3,56)$. 
Entretanto, o teor de cinza encontrado assemelha-se ao valor determinado por Lorini $(2017)$ de $(2,69)$, encontrando-se abaixo dos valores descritos na literatura para a faixa de variação de teores de cinzas na castanha-do-brasil.

É importante ressaltar que o teor de minerais pode variar de acordo com o clima e, principalmente, com o tipo de solo, podendo haver predominância de um ou outro mineral que a planta pode absorver em maior ou menor quantidade, sendo o fósforo, dentre os minerais, o componente mais abundante em sementes da castanha-do-pará, seguido pelo potássio, magnésio e cálcio (SILVA et al., 2010).

A castanha-do-brasil é uma fonte natural rica em Selênio, que contribui no suprimento das necessidades diárias desse mineral. Segundo a FAO/OMS, o valor diário recomendado de Se para adultos é de 34?g (BRASIL, 2005). Segundo Thomson et al. (2008), o consumo de duas unidades de castanha é capaz de elevar a atividade da glutationa peroxidase assim como 100 ?g de selenometionina. Portanto, isso evitaria a necessidade do uso deste suplemento em populações deficientes em Se. A composição nutricional da castanha-do-brasil revela-se superior tanto neste trabalho quanto na literatura, entretanto, para que o alimento seja saudável, certos parâmetros devem ser considerados.

Desta forma, realizou-se a análise de bactérias mesófilas, coliformes fecais e bolores e leveduras objetivando identificar as condições da cadeia de produção e delimitar o perigo ao consumidor, para atender as premissas de segurança alimentar. Os resultados das análises foram avaliados segundo os parâmetros microbiológicos contemplados pela Resolução Diretoria Colegiada - RDC N¹2/2001, da ANVISA e podem ser visualizados na figura 1.

Cabe ressaltar que, embora a amostra analisada esteja dentro dos limites estabelecidos pela legislação, é de extrema importância que medidas preventivas sejam adotadas ao longo de toda a cadeia produtiva para se evitar a contaminação. A tabela 2 apresenta os resultados obtidos das análises de contagem de bactérias mesófilas aeróbias, contagem total de bolores e leveduras e coliformes totais e termotolerantes, realizadas nas amostras do tofu de castanha-do-brasil.

Outra grande questão relacionada à castanha-do-brasil são os possíveis riscos 

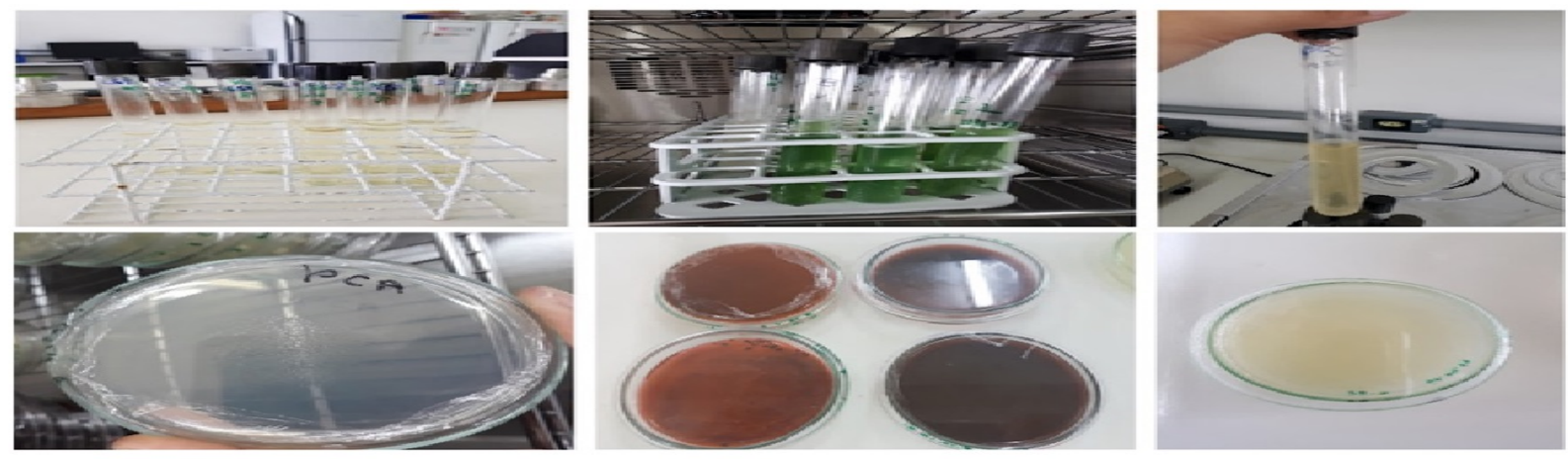

Figura 1. Análise microbiológica do queijo de castanha.

de contaminações aos quais sua cadeia produtiva está sujeita, podendo ser perigos de origem biológica, química e física. Deste modo, é imprescindível a aplicação de boas práticas de manejo da castanha-do-brasil, principalmente na etapa de pós-colheita, pois nesta etapa frequentemente ocorre a contaminação por aflatoxinas, produzidas por fungos (Aspergillus flavus, A. parasiticus e A. nomius) (COSTA, et al., 2012).

Tabela 2. Resultados microbiológicos do queijo tipo tofu $100 \%$ da castanhas-do-brasil:

\begin{tabular}{l|l|l|l}
\hline MEIOS DE CULTURAS & $\begin{array}{l}\text { Mesófilas } \\
\text { (NMP/g) }\end{array}$ & $\begin{array}{l}\text { Bolores } \\
\text { leveduras } \\
(\text { UFC } / g)\end{array}$ & $\begin{array}{l}\text { Coliformes } \\
\text { totais a } 45^{\circ} \mathrm{C} \\
(\text { UFC/g) }\end{array}$ \\
\hline EMB & $92(\mathrm{NMP} / \mathrm{g})$ & Não se aplica & $\begin{array}{l}\text { Não se } \\
\text { aplica }\end{array}$ \\
\hline E.C & Não se aplica & Não se aplica & Ausente \\
\hline Caldo Lauril & Ausente & Não se aplica & Ausência \\
\hline Caldo verde brilhante & Não se aplica & Não se aplica & Ausente \\
\hline PCA (Plate Count Agar) & Ausente & Não se aplica & $\begin{array}{l}\text { Não se } \\
\text { aplica }\end{array}$ \\
\hline Sabourau & Não se aplica & Ausência & $\begin{array}{l}\text { Não } \\
\text { aplica }\end{array}$ \\
\hline
\end{tabular}

As diferentes formulações resultaram em três diferentes produtos (figura 1), os quais apresentaram as seguintes características: A fração de tofu de $50 \%$ de castanhado-brasil e de soja mostrou-se com textura muito pastosa, semelhante à textura de re- 
queijão devido à alta concentração de lipídios das matérias-primas; apresentou cor marrom clara e de sabor característicos ao de soja. A fração de tofu de $75 \%$ de castanhado-brasil e 35\% de soja apresentou massa mais firme, consistente, de coloração marrom claro e sabor característico predominante da soja. A fração de tofu de $100 \%$ de castanha-do-brasil mostrou-se com textura firme e macia, de cor e sabor característicos de castanha-do-brasil.

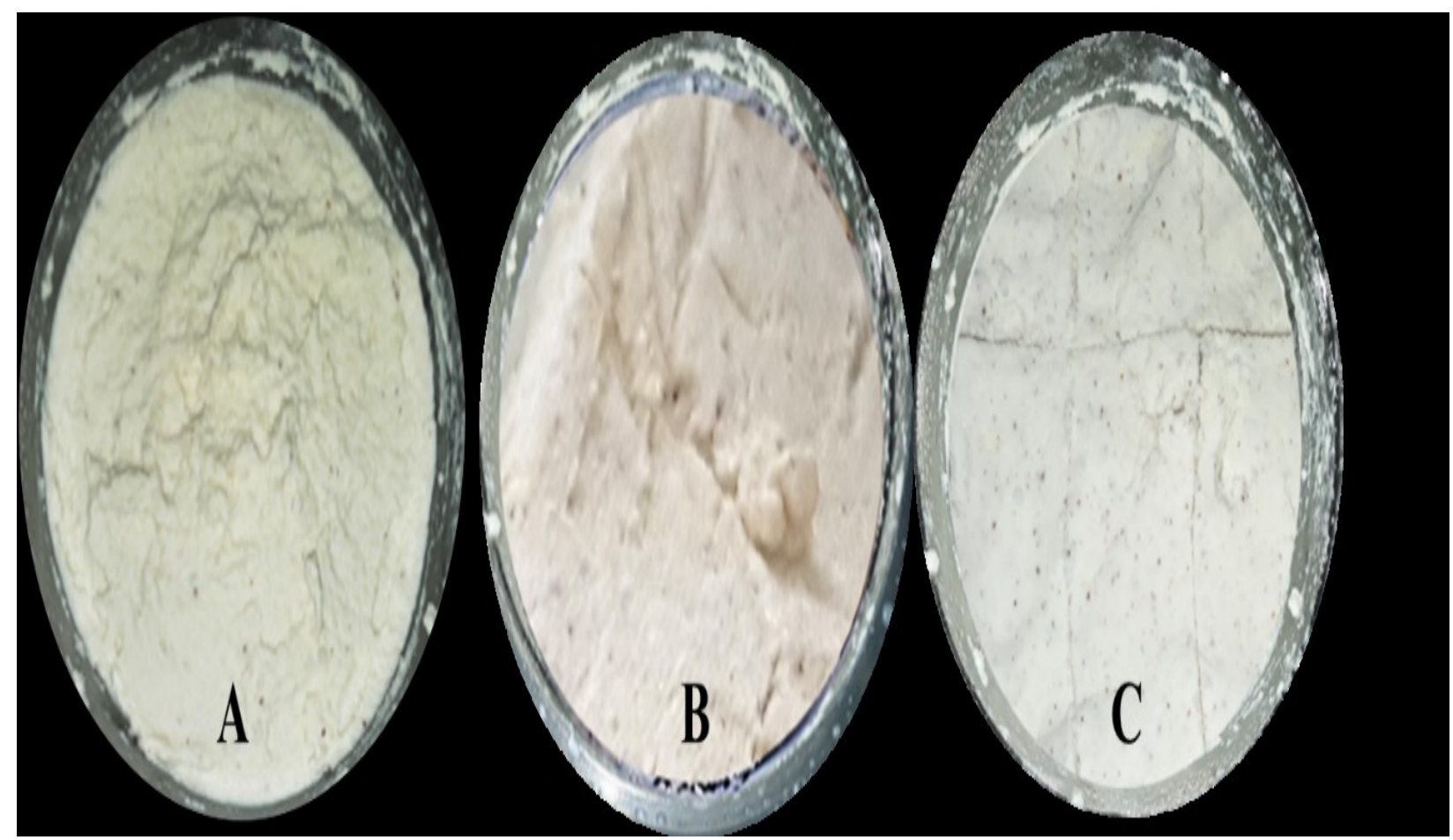

Figura 2. Formulação do queijo de castanha. A) $50 \%$ castanha-do-brasil e $50 \%$ de soja; B) $75 \%$ castanha-do-brasil e $35 \%$ de soja e C) $100 \%$ castanha-do-brasil.

Houve diferença na aceitabilidade do queijo contendo apenas castanha e do queijo contendo a mistura de castanha e soja (figura 3). Com relação à avaliação global, constatou-se que o queijo com $100 \%$ de castanha foi a formulação mais aceita. Esses dados foram evidenciados na análise sensorial nos aspectos relacionados ao sabor (73\%), aparência (68\%) e textura (65\%).

O queijo tipo tofu de concentração 75\% castanha-do-brasil apresentou boa aceitabilidade de aparência (68\%) e aroma (60\%), mais baixa em relação ao sabor (27\%) e a textura (22\%). Isso pode ser explicado devido ao fato do sabor da soja sobressair ao sabor da castanha-do-brasil. Na avaliação de intenção de compra, o índice de rejeição do queijo $100 \%$ foi baixo, em que apenas $16 \%$ dos provadores não comprariam, en- 


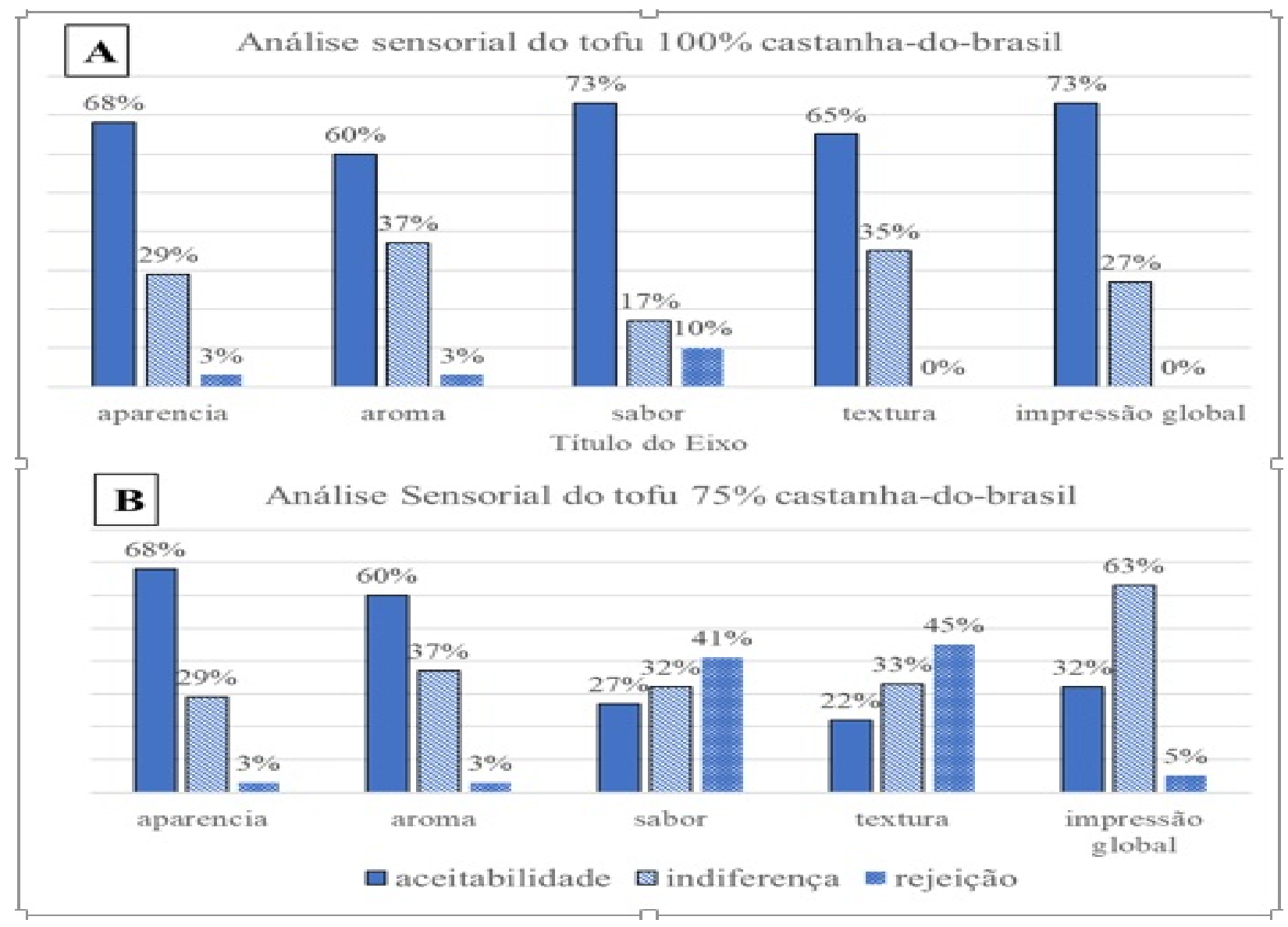

Figura 3. Análise sensorial do queijo de castanha. A) Formulação com $100 \%$ de castanha e B) Formulação com $75 \%$ de castanha.

quanto de $52 \%$ afirmaram que certamente comprariam. Esse comportamento corrobora o teste de aceitação dos itens de forma individual, demonstrando a maior preferência dos provadores pelo queijo de castanha (100\%).

\section{CONCLUSÃO}

Este é um trabalho preliminar que subsidia estudos futuros para o aprimoramento das análises e investigações do tempo de prateleira e otimização da elaboração desse produto. Os resultados encontrados demonstram a potencialidade desse produto que comprovadamente apresenta efeitos benéficos para o organismo humano e que pode ser utilizado na indústria alimentícia como um produto beneficiado, o que poderia agregar valor à matéria prima e servir de renda econômica alternativa para os produtores locais de castanha-do-brasil. Além disso, torna-se uma alternativa a consumidores que não ingerem alimentos derivados de animais ou que apresentam, limitação no metabolismo 
relacionados ao leite de origem animal.

Os resultados da avaliação tecnológica mostraram que a castanha-do-Brasil pode ser utilizada como base para a elaboração de queijo tipo tofu. Esta formulação se enquadra como uma alternativa de produto para os consumidores veganos/vegetarianos, intolerantes à lactose, alérgicos ao leite de vaca, dislipidêmicos, e a pessoas que buscam por alimentos mais saudáveis.

\section{Referências}

ABONIZIO, Juliana. Conflitos à mesa: vegetarianos, consumo e identidade. Revista Brasileira de Ciências Sociais. vol.31, n.90, pp.115-136. Cuiabá ? MT, Brasil, 2016.

ANDRADE, Rafael Gava de. Classificação Da Castanha-do-brasil Por Origem e Seleção De Suas Amêndoas Utilizando Visão computacional. Dissertação (Mestrado) Engenharia Elétrica e Área de Concentração de Processamento De Sinais e Instrumentação. Escola de Engenharia de São Carlos da Universidade de São Paulo. São Carlos, 2010.

ANVISA, Agência Nacional de Vigilância Sanitária. Resolução RDC nํ269, de 22 de setembro de 2005. O "Regulamento Técnico Sobre a Ingestão Diária Recomendada (IDR) de Proteína, Vitaminas e Minerais”. Brasil, 23 de setembro de 2005.

APHA. American Public Health Association Compendium of Methods for the Microbiological Examination of Foods. 4thed. Washington, DC, 2001. Chapter 3, p.31.

ARAÚJO, J.M.A. Química de alimentos: teoria e prática. 3.ed. rev. e ampl. Viçosa, MG: UFV, 2004. 210p.

BALDI, Maria Eugenia; PENTEADO, Patricia Teixeira Padilha da Silva; CARDOSO, GuiIherme; SOBRAL, Marina Gomes; SOUZA, Vanessa Rodrigues de. Castanha-do-pará (bertholletia excelsa bonpl.): composição química e sua importância para saúde. Brazil nut (bertholletia excelsa bonpl.): chemical composition and its health benefits. Rev. Visão Acadêmica, Curitiba, v.15, n.2, Abr. - Jun./2014.

BENASSI, Vera de Toledo; FELBERG, llana, ALVARENGA, André L. B., MANDARINO, José M. G. Tofu. 39 p.: il. - (Coleção Agroindústria Familiar). Embrapa Informação Tecnológica - Brasília, DF, 2007.

BEUCHAT, L. R.; COUSIN, M. A. Yeasts and molds. In: DOWNES, F. P.; ITO, K. (eds). Compendium of methods for the microbiological examination of foods. 4 ed. Washington: APHA, 2001. p. 209-215.

BRASIL, ANVISA - Agência Nacional de Vigilância Sanitária. Resolução $n^{\circ} 360$, de 23 de dezembro de 2003. Dispõe sobre Rotulagem Nutricional de Alimentos Embalados. D i s p o n í v e I em: < http://www.anvisa.gov.br/legis/resol/2003/rdc/360_03rdc.htm>. Acessado em 20 de setembro de 2018.

BRASIL, Ministério da Saúde. Resolução n-12, de 02 de janeiro de 2001. Aprova o 
Regulamento Técnico sobre padrões microbiológicos para alimentos. Diário Oficial da Republica Federativa do Brasil. Brasília, DF, 10 jan. 2001. Seção 1, p. 46-53.

BRASIL. Ministério da Agricultura, Pecuária e Abastecimento. Projeto de Monitoramento da Castanha do Brasil. Relatório de Atividades. 2002. Brasília/DF, 2002.

CENTRO VEGETARIANO. Tipos de vegetarianos. 5 out 2002. Disponível em:<http://www.centrovegetariano.org/index.php?article_id=70>. Acessado em: 10 agosto 2019.

COSTA, D. A.; ÁlVARES, V. S.; CASTRO, I. M.; FONSECA, F. L. Quantificação de aflatoxinas em castanha-do-brasil oriundas de três localidades do Estado do Acre. (Aflatoxins survey in Brazil nuts from three locations in the state of Acre, Brazil.) Tropical Plant Pathology 37 (Suplemento) - Resumo 230 , 45ํㅡㄹ Congresso Brasileiro de Fitopatologia - agosto, Manaus - AM, 2012.

DOWNES, F. P.; ITO, K. (Ed.). Compendium of methods for the microbiological examination of foods, 4th edition, Washington: American Public Health Association, 2001, 600p.

DUTRA-DE-OLIVEIRA J. E; MARCHINI J. S. Ciências Nutricionais: Aprendendo a Aprender. 1.ed. São Paulo: Sarvier, 1998.

FELBERG, I; DELIZA, R; GONÇALVES, E.B; ANTONIASSI, R. Bebida mista de extrato de soja integral e castanha-do-Brasil: caracterização físico-química, nutricional e aceitabilidade do consumidor. Alim. Nutr., Araraquara, v. 15, n. 2, p. 163-174, 2004.

FREITAS, Jullyana Borges; NAVES, Maria Margareth Veloso Composição química de nozes e sementes comestíveis e sua relação com a nutrição e saúde. Rev. Nutr., Campinas, 23(2):269-279, mar. /abr., 2010.

IBGE. Instituto Brasileiro de Geografia e Estatística. Pesquisa de orçamentos familiares 2008-2009: tabelas de composição nutricional dos alimentos consumidos no Brasil / IBGE, Coordenação de Trabalho e Rendimento. Rio de Janeiro, 2011. Disponível em: https://servicodados.ibge.gov.br/Download/Download.ashx?http=1\&u=biblioteca.ibge.gov.br/vi sualizacao/livros/liv50002.pdf>. Acesso em: 24 setembro de 2018.

IBOPE. Instituto Brasileiro de Opinião Pública e Estatística. Hábitos de saúde e de consumo da mulher brasileira. 2011. Disponível em<http://www.ibope.com.br/calandraWeb/servlet/CalandraRedirect? temp=5\&proj=PortallBOPE\&pub=T\&db=caldb\&comp=IBOPE+M\%E Ddia\&docid=09 2582CC36D2FBFB8325784800405FB8>. Acesso em: 4 setembro de 2017.

IBOPE. Instituto Brasileiro de Opinião Pública e Estatística. Pesquisa de opinião pública sobre vegetarianismo. 2018.Disponível em:<http://www.svb.org.br/images/Documentos/JOB_0416_VEGETARIANISMO.pdf>.

Acessado em: 9 maio de 2018.

INSTITUTO ADOLFO LUTZ. Normas analíticas do instituto Adolfo Lutz: Métodos Químicos e Físicos para análise de alimentos. São Paulo: Instituto Adolfo Lutz, 2008.

KORNACKI, J. L.; JOHNSON, J. L. Enterobacteriaceae, coliforms, and Escherichia coli as quality and safety. In: DOWNES, F. P.; ITO, K. Compendium of methods for the 
microbiological examination of foods. 4 ed. Washington: APHA, 2001. p. 9-81.

LORINI, Alexandre; WOBETO, Carmen; PEREIRA; Claudineli Cássia Bueno da Rosa Maristela; BOTELHO, Sílvia de Carvalho Campos. Qualidade microbiológica e físicoquímica de castanhas-do-brasil. Rev. Higiene Alimentar - Vol.31 - nํ 264/265 - Janeiro/Fevereiro de 2017.

MARTINS, M. Interação entre aflatoxinas, selênio e radioatividade em castanhado-Brasil (Bertholletia excelsa). [Dissertação de mestrado, Universidade Federal do Amazonas, Manaus - AM, 2010.

PAULETO, B. F.; FOGAÇA, A. O. Avaliação da composição centesimal de tofu e okara. Disciplinarum Scientia. Série: Ciências da Saúde, Santa Maria, v.13, n.1, p.85-95, 2012.

SILVA, RF; ASCHERI, JLR; SOUZA, JML. Influência do processo de beneficiamento na qualidade de amêndoas de castanha-do-brasil. Rev. Ciênc Agrotecnol, Lavras, v.34, n.2, p.445-450, 2010.

SOUZA, M. L. Processamento de cereais matinais extrusados de castanha-doBrasil com mandioca. 2003. 191 p. Tese. (Doutorado em Tecnologia de Alimentos) - Faculdade de Engenharia de Alimentos, Universidade Estadual de Campinas, Campinas, 2003.

SOUZA, ML; MENEZES, HC. Processamentos de amêndoa e torta de castanha-dobrasil e farinha de mandioca: parâmetros de qualidade. Rev. Ciência e Tecnologia de Alimentos, Campinas, v.24, n.1, p.120-128, 2004.

TACO. Tabela Brasileira de Composição de Alimentos (TACO). 4a Ed. Campinas, UNICAMP, São Paulo: 2011. Disponível em: $<$ http://www.unicamp.br/nepa/taco/contar/taco_4_edicao_ampliada_e_revisada.pdf?arq uivo=taco_4_versao_ampliada_e_revisada.pdf >. Acesso em: 28 out. 2018.

TAFFAREL, J.A.S. Desenvolvimento de alimentos veganos tipo "queijo" e tipo "requeijão". 2012. Monografia (Graduação) Engenharia de Alimentos, Instituto de Ciência e Tecnologia de Alimentos. Universidade Federal do Rio Grande do Sul. Porto Alegre/RS, 2012.

THOMSON, C. D et al. Brazil nuts: an effective way to improve selenium status. American Journal of Clinical Nutrition, v. 87, n 2, p 379-384, 2008. 